Journal of Agricultural Sciences
(Tarim Bilimleri Dergisi)

\title{
Internal Transcribed Spacer (ITS) Fails Barcoding of the Genus Neotinea Rchb.f. (Orchidaceae)
}

\author{
Kaan HÜRKAN ${ }^{\text {a* (D), Kemal Melih TAŞKIN }}{ }^{b}$ (iD)

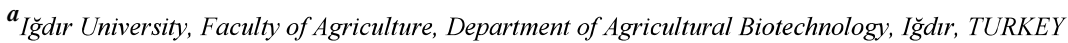 \\ ${ }^{b}$ Çanakkale Onsekiz Mart University, Faculty of Sciences and Arts, Department of Molecular Biology and Genetics, Çanakkale, TURKEY \\ ARTICLE INFO \\ Research Article \\ Corresponding Author: Kaan HÜRKAN, E-mail: kaanhurkan@hotmail.com \\ Received: 05 September 2019 / Revised: 19 October 2019 / Accepted: 29 October 2019 / Online: 18 January 2021
}

\section{ABSTRACT}

Internal Transcribed Spacer (ITS) is one of the most used barcoding regions for the molecular phylogenetics and barcoding of orchids. Our aim in this study is to test the reliability of ITS on barcoding of closely related Neotinea spp., including Neotinea tridentata, Neotinea ustulata subsp. ustulata and Neotinea ustulata subsp. aestivalis, by comparing it to the $a c c \mathrm{D}-p s a \mathrm{I}$ intergenic spacer of the plastid DNA. Both ITS and $a c c D-p s a \mathrm{I}$ regions were amplified by specific primer sets and sequenced. Phylogenetic trees were regenerated by using Maximum Parsimony approach. The results showed that ITS separated some $N$. tridentata samples of Turkish, Greek, Hungarian and Croatian samples from the others on the phylogenetic trees due to the incomplete lineage sorting. In contrast to ITS, the accD-psaI marker could successfully separate $N$. tridentata and $N$. ustulata samples according to a priori species classification. Our findings refer to a hybridisation story between some $N$. tridentata and $N$. ustulata. We propose not to use ITS sequences directly as a barcode and to reconstruct the phylogeny of the Neotinea group. Instead, the inclusion of other nuclear regions such as $L F Y, A D H$, etc., or utilisation of whole genome sequencing could give better barcoding results.

Keywords: Orchids, accD-psaI, DNA barcoding, phylogenetic incongruence.

(C) Ankara University, Faculty of Agriculture

\section{Introduction}

The orchid family (Orchidaceae) is the second largest flowering plant family represented by 899 genera and 27801 species (The Plant List 2013). Therefore, it is necessary to develop a reliable molecular identification method. Since the 1990s, using molecular markers on the phylogenetic studies of orchids have been increasing incrementally (Chase et al. 2000; Bateman et al. 2003; Sramko et al. 2014). Plant taxonomists have used short sequences of both ribosomal deoxyribonucleic acid (rDNA) and chloroplast deoxyribonucleic acid (cpDNA) as molecular markers to identify species and to reconstruct phylogeny (Zimmer \& Wen 2012). Rapidly evolving DNA regions are needed for species-level barcoding (Sramkó et al. 2011; Zimmer \& Wen 2012). The Internal Transcribed Spacer of the nuclear ribosomal 18S-5.8S-26S cistron (ITS) is one of the most extensively used molecular marker in orchid identification and molecular phylogenetic since the 1990s (Baldwin et al. 1995; Pridgeon et al. 1997; Bateman et al. 2003; Álvarez \& Wendel 2003; Shipunov et al. 2004; Gulyás et al. 2005; Nieto-Feliner \& Rosselló 2007; Hollingsworth 2008; Sramko et al. 2014; Li et al. 2015). The main advantages of ITS are (1) universality of primer sets (White et al. 1990), (2) ease of amplification even from historic specimens (i.e., herbarium specimens) due to multi-copy characteristic, and (3) favourable size of the region ( $700 \mathrm{bp}$ ) (Baldwin et al. 1995). Some researchers point out the concerted evolution of ITS region (Bailey 2003; Gulyás et al. 2005; Pillon et al. 2007; Nieto-Feliner \& Rosselló 2007). Concerted evolution is a process that homogenizes the rDNA array within an organism and reduces intra-individual variation (Liao 2008). $a c c \mathrm{D}-p s a \mathrm{I}$ barcoding region covers partial acetyl-CoA carboxylase enzyme $(a c c D)$ and Photosystem I ( psaI) coding regions and an intergenic region on the chloroplast genome.

In this study, we would like to test the utilities of ITS and accD-psaI regions for DNA barcoding of closely related Neotinea (Rchb.f.) taxa; Neotinea tridentata (Scop.) R. M. Bateman, Pridgeon \& M. W. Chase, Neotinea ustulata subsp. ustulata (L.) R. M. Bateman, Pridgeon \& M. W. Chase and Neotinea ustulata (L.) R. M. Bateman, Pridgeon \& M. W. Chase subsp. aestivalis (Kümpel) Kolník, Vlčko \& Dítě by comparing the topology of the phylogenetic trees. 


\section{Material and Methods}

\subsection{Plant material and DNA extraction}

The field-collected leaf samples placed in silica-gel sachets and stored at room temperature until DNA extraction. The samplings of N. tridentata, N. ustulata subsp. ustulata, N. ustulata subsp. aestivalis, Neotinea maculata (Desf.) Stearn and Neotinea conica (Willd.) R. M. Bateman, were obtained from Mediterranean, west sub-Mediterranean, middle subMediterranean, Balkan sub-Mediterranean and east sub-Mediterranean regions (Figure 1: 1A and 1B). Altogether, we analysed 23 samples of Neotinea spp. from the field and 9 DNA sequences from the nucleotide collection GenBank (Supplementary Data 1). We chose Ophrys phrygia H. Fleischm. \& Bornm. (Genbank accession no: MH050859) and Platanthera dilatata (Pursh) Lindl. ex L. C. Beck (Genbank accession no: JX484921) as out-groups.
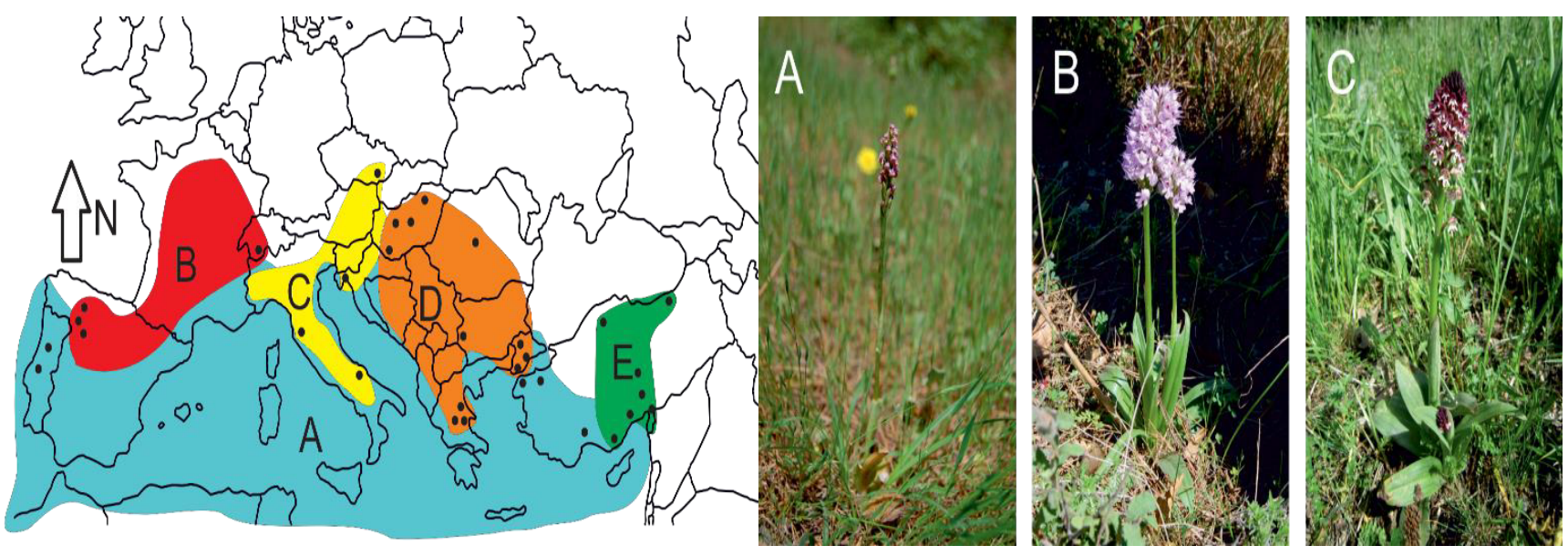

Figure 1- 1A; Sampling map. A: Mediterranean, B; West sub-Mediterranean, C; Mid sub-Mediterranean, D; Balkan subMediterranean and E; East sub-Mediterranean. (Platanthera dilatata was excluded). 1B; Images of Neotinea maculata (A), Neotinea tridentata (B) and Neotinea ustulata (C). The image of N. ustulata (Vladan Djordjevic).

The DNA extraction was performed according to the cetyltrimethylammonium bromide (CTAB) protocol (Doyle \& Doyle 1990). Approximately $10 \mathrm{mg}$ of dried leaves used for the extraction.

\subsection{Choice of molecular markers for molecular barcoding}

We used ITS as a nuclear-molecular marker to test its molecular barcoding utilities for Neotinea spp. which were collected from a wide geographic range. We also added the plastid-encoded $a c c \mathrm{D}-p s a$ I intergenic region to be compared with ITS. Thus, we would be able to check the hybridisation origin of $N$. tridentata, as well.

\subsection{PCR amplification, sequencing and phylogenetic reconstruction}

We used angiosperm-specific ITS1A (Gulyás et al. 2005) and universal ITS4 (White et al. 1990) primer pair to amplify the whole ITS region. $25 \mu \mathrm{L}$ of the PCR reaction mixture consisted of 0.1 volume of 10x High-Fidelity Buffer (Fermentas, USA), $0.5 \mu \mathrm{L}$

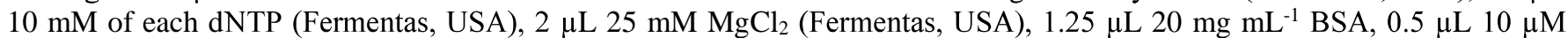
primers (Thermo Scientific, USA), $0.1 \mu \mathrm{L} 5$ Unit High-Fidelity polymerase (Fermentas, USA), $16.65 \mu \mathrm{L}$ water and $1 \mu \mathrm{L}(\sim 5 \mathrm{ng}$ $\mu \mathrm{L}^{-1}$ ) genomic DNA. PCR amplification of ITS was performed on BIO-RAD PTC-200 thermal cycler using the following PCR profile: $94{ }^{\circ} \mathrm{C}$ for $2 \mathrm{~min}$ first denaturation, followed by 33 cycles of denaturation for $20 \mathrm{~s}$ at $94{ }^{\circ} \mathrm{C}$, annealing for $30 \mathrm{~s}$ at $51{ }^{\circ} \mathrm{C}$ and extension for $1 \mathrm{~min}$ at $72{ }^{\circ} \mathrm{C}$ and finalized by final extension for $10 \mathrm{~min}$ at $72{ }^{\circ} \mathrm{C}$. PCR products were then sent to Macrogen Inc. (The Netherlands) for Sanger sequencing (Applied Biosystems 3100 Genetic Analyzer) using ITS1A primer. Double signal peaks and Additive polymorphic sites (APS) were coded according to the International Union of Pure and Applied Chemistry (IUPAC) ambiguity symbols. We annotated the whole ITS region into the parts ITS1, 5.8s and ITS2 according to the sequences retrieved from the GenBank.

We used accD-f and psaI-r primer pair to amplify the accD-psaI region (Small et al. 1998). The PCR mixture was the same used for ITS amplification. PCR profile was applied as follows; $94{ }^{\circ} \mathrm{C}$ for $3 \mathrm{~min}$ first denaturation, followed by 34 cycles of denaturation for $30 \mathrm{~s}$ at $94{ }^{\circ} \mathrm{C}$, annealing for $30 \mathrm{~s}$ at $55^{\circ} \mathrm{C}$ and extension for $1 \mathrm{~min}$ at $72{ }^{\circ} \mathrm{C}$ and finalized by a final extension for $10 \mathrm{~min}$ at $72^{\circ} \mathrm{C}$. Amplified samples were sequenced in both directions using accD-f and psaI-r primers. 
For the ITS and $a c c \mathrm{D}-p s a \mathrm{I}$ regions, the sequences were aligned by ClustalW (Larkin et al. 2007) under the bioinformatics software package Geneious R8 (Kearse et al. 2012). We used Maximum Parsimony (MP) heuristic search by PAUP 4.0a (build 159) (Swofford 2003). The MP-heuristic-search settings were: trees obtained from 1000 random replicates holding one tree at each step for stepwise addition, gaps are treated as missing, out-group: $O$. phrygia (ITS) and $P$. dilatata (accD-psaI), steepest descent option not in effect, and tree-bisection-reconnection (TBR) was used as branch swapping.

\section{Results}

\subsection{Information obtained from DNA markers}

ITS and $a c c \mathrm{D}-p s a \mathrm{I}$ regions were successfully amplified and sent to the sequencing service. The sequence files were imported into Geneious R8 software and checked for quality values. We excluded three samples since sequencing qualities of two samples from Italy, $N$. tridentata from Mt. Gargano and Toskana for ITS and accD-psaI, and one sample from Hungary, N. tridentata from Tokaj, for ITS were unacceptable for both ITS regions. We detected three interspecific length polymorphisms among five studied taxa; $N$. conica has 613 bp ITS, $N$. maculata has 609 bp ITS length. N. tridentata, N. ustulata subsp. ustulata and $N$. ustulata subsp. aestivalis have identical 616 bp ITS length. Whereas those polymorphisms are observed on ITS1 (ranged 234$243 \mathrm{bp}$ ) and ITS2 (ranged 217-222 bp) parts, there was no length polymorphism on the coding 5.8S part (Table 1). There was no length polymorphism on the accD-psaI region.

Table 1- ITS length polymorphisms on Neotinea spp

\begin{tabular}{|c|c|c|c|c|c|c|}
\hline \multirow{2}{*}{ Sample } & \multirow{2}{*}{ Accession No } & \multirow{2}{*}{ Collecting site } & \multicolumn{4}{|c|}{ Lengths in base-pair } \\
\hline & & & ITS1 & $5.8 S$ & ITS2 & Total Length \\
\hline N. conica & AY364880 & Caceres-Spain & 243 & 153 & 217 & 613 \\
\hline N. maculata & AM711744 & Kythera-Greece & 234 & 153 & 222 & 609 \\
\hline N. maculata & MH050840 & Likouria-Greece & 234 & 153 & 222 & 609 \\
\hline N. maculata & AY364873 & Tras os Montes-Portugal & 234 & 153 & 222 & 609 \\
\hline All N. tridentata samples & All Samples & All Samples & 242 & 153 & 221 & 616 \\
\hline
\end{tabular}

Table 2- Initial comparison of DNA markers used in the study. O. phrygia (ITS) and $P$. dilatata (accD-psaI) are treated as outgroups relative to in-group samples

\begin{tabular}{|c|c|c|c|c|c|c|c|c|c|c|c|}
\hline \multirow{3}{*}{$\begin{array}{c}\text { DNA } \\
\text { Region }\end{array}$} & \multirow{3}{*}{ Origin } & \multirow{3}{*}{ Length range } & \multirow{2}{*}{\multicolumn{3}{|c|}{$\begin{array}{l}\text { Number of in-group } \\
\text { polymorphic sites }\end{array}$}} & \multirow{3}{*}{$\begin{array}{l}\text { Parsimony } \\
\text { informative } \\
\text { characters }\end{array}$} & \multirow{3}{*}{$\begin{array}{c}\text { Aligned } \\
\text { length }\end{array}$} & \multicolumn{4}{|c|}{ Variability } \\
\hline & & & & & & & & \multicolumn{2}{|c|}{ Number } & \multicolumn{2}{|c|}{ Percentage } \\
\hline & & & ITS1 & $5.8 S$ & ITS2 & & & $\begin{array}{c}\text { Out- } \\
\text { group }\end{array}$ & $\begin{array}{c}\text { In- } \\
\text { group }\end{array}$ & $\begin{array}{c}\text { Out- } \\
\text { group }\end{array}$ & $\begin{array}{c}\text { In- } \\
\text { group }\end{array}$ \\
\hline ITS & Nucleus & $609-623$ & $\begin{array}{c}8 \\
(3.3 \%)\end{array}$ & $\begin{array}{c}0 \\
(0 \%)\end{array}$ & $\begin{array}{c}3 \\
(0.9 \%)\end{array}$ & 37 & 632 & 111 & 44 & $17.56 \%$ & $7.0 \%$ \\
\hline $\begin{array}{c}a c c \mathrm{D}- \\
p s a \mathrm{I}\end{array}$ & Chloroplast & 923 & - & - & - & 8 & 933 & 8 & 3 & $0.86 \%$ & $0.32 \%$ \\
\hline
\end{tabular}

Accordingly, the sequence variability of each DNA marker (Table 2) ITS region outperforms the chloroplast region accD$p s a \mathrm{I}$ in several variable positions (44 to 3 in-group), percentage within the aligned length (7.0\% to $0.32 \%$ in-group) and parsimony informative characters (37 to 8). This comparison also shows that the ITS1 part of the ITS region has more variable sites $(3.3 \%$ to $0.9 \%$ ) than the ITS2 part. The aligned length was calculated as $632 \mathrm{bp}$ for the ITS region and $933 \mathrm{bp}$ for $a c c \mathrm{D}-$ psaI region. The protein coding 5.8S part has no variable sites on the studied samples, as expected. We observed APS on the chromatogram data of ITS sequences caused by the multi-copy nature and incomplete concerted evolution feature of the region (Table 3 and Figure 2). 
Table 3- Additive Polymorphic Sites (APS) on ITS sequences

\begin{tabular}{llll}
\hline Sample & Number of APS & Position (bp) & $\begin{array}{l}\text { Nucleotides } \\
\text { (IUPAC Symbols) }\end{array}$ \\
\hline N. tridentata (Balıkesir-TR) & 1 & 432 & G or A (R) \\
N. tridentata (Çanakkale-TR) & 1 & 513 & G or A (R) \\
N. ustulata subsp. aestivalis (Kiralyko-RO) & 2 & 513,606 & G or A (R) \\
N. ustulata (Velka nad Velickou-CZ) & 3 & $513,514,606$ & G or A (R) \\
N. tridentata (Adana-TR) & 1 & 555 & G or A (R) \\
N. tridentata (Trabzon-TR) & 1 & 555 & G or A (R) \\
N. tridentata (Antalya-TR) & 1 & 555 & G or A (R) \\
\hline
\end{tabular}
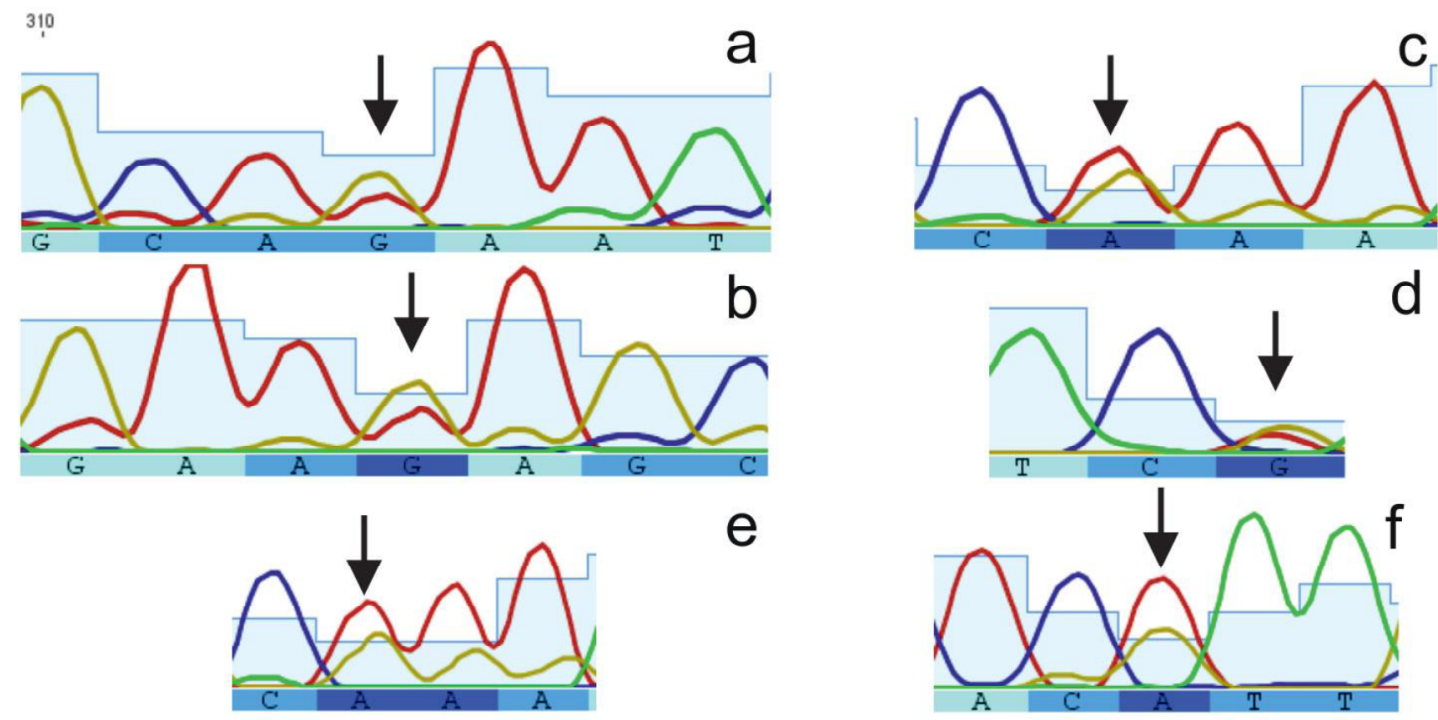

e
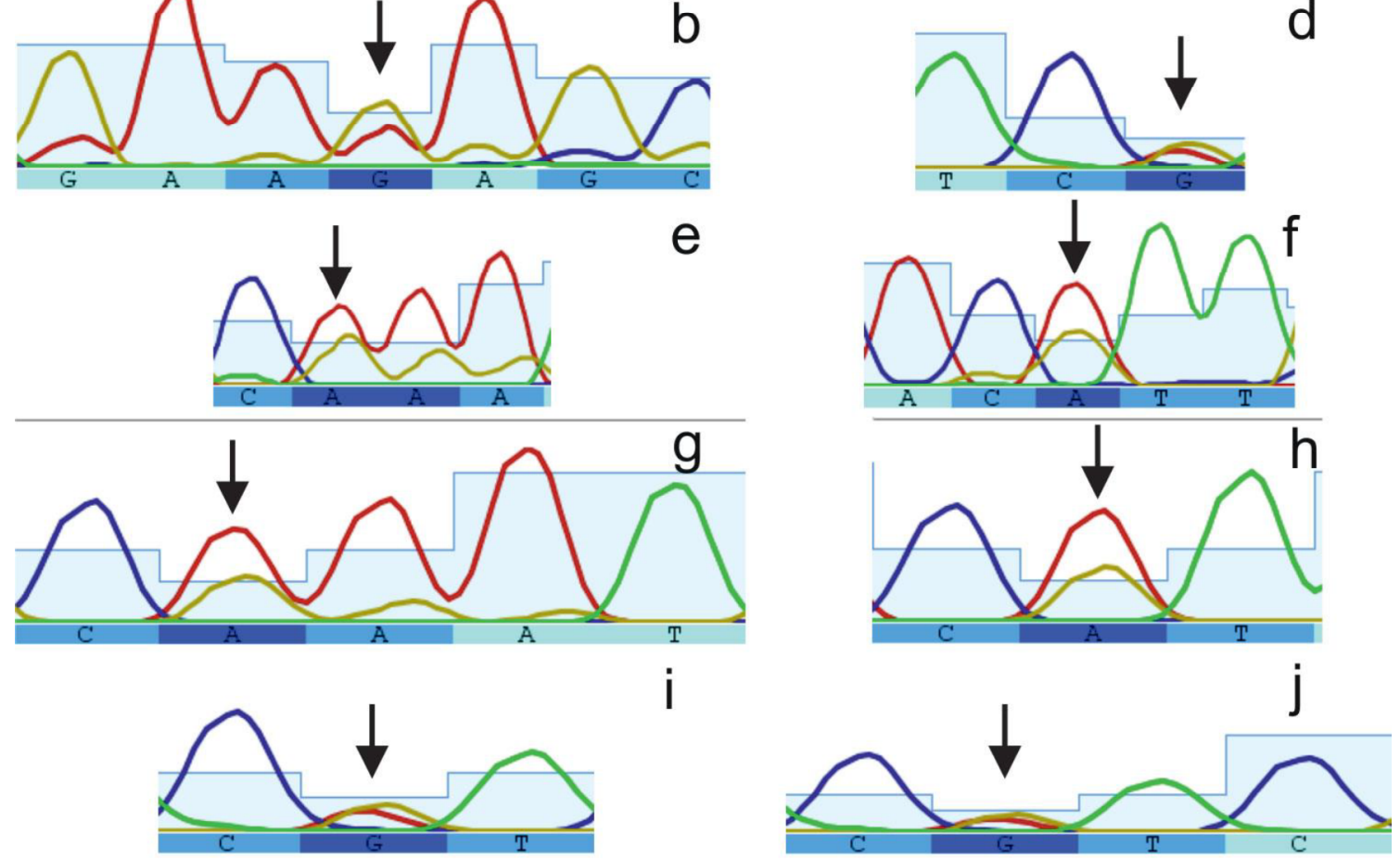

Figure 2- Additive Polymorphic Sites (APS) of ITS sequences

\subsection{Phylogenetic reconstruction}

The MP phylogenetic analysis of the ITS region used 37 parsimony-informative characters and retained one most-parsimonious tree in 8028 rearrangement trials. The score of the best tree was 119. The MP tree showed moderate to high bootstrap support values (75 to 100$)$.

On the ITS MP tree, O. phrygia was designated as the out-group and main clades consisted of $N$. maculata and $N$. tridentata/N. ustulata block. N. tridentata samples from Turkey (Adana, Antalya and Trabzon), Hungary (Siklos) and Croatia (Ucka) were apart from the main $N$. tridentata/N. ustulata clade. ITS sequences of those samples showed differences from other $N$. tridentata samples on the alignment as well since having APS. N. tridentata samples collected from Adana, Antalya and 
Trabzon samples have APS on the $559^{\text {th }}$ position of the alignment $\left(555^{\text {th }}\right.$ position on the sequence file), and on those positions, the nucleotides were either Adenine or Guanine. N. tridentata samples from Hungary (Siklos) and Croatia (Ucka) have different nucleotide (Thymine instead of Cytosine) on the $593^{\text {rd }}$ position of the alignment $\left(589^{\text {th }}\right.$ position on the sequence file). $N$. tridentata sample from Greece (Pelion) had one nucleotide difference (Cytosine instead Thymine) on the $229^{\text {th }}$ position of the alignment $\left(226^{\text {th }}\right.$ position on the sequence file) than other $N$. tridentata samples. There was no APS on the sequence of those samples.

According to the ITS MP tree, N. tridentata samples collected from Adana, Trabzon, Antalya (Turkey), Siklos (Hungary), Ucka (Croatia) and Pelion (Greece) are sister to other $N$. tridentata samples. This results in polytomy among $N$. tridentata.

The MP-phylogenetic analysis of the accD-psaI region used 8 parsimony-informative characters and retained one mostparsimonious tree in 28776 rearrangement trials. The score of the best tree was 381. On the phylogram of accD-psaI sequences, $N$. tridentata samples placed together on one clade did not separate from each other as on the ITS tree (Figure 3). Three $N$. ustulata samples from Bulgaria, Czech Republic and Romania were separated on the tree, and this separation was highly supported by bootstrap. However, $N$. ustulata subsp. ustulata from Hungary was grouped with the $N$. tridentata samples. $N$. tridentata showed polytomy on the tree and, therefore, $N$. ustulata and $N$. tridentata samples were placed on the same branch.

\section{Discussion}

ITS region of nuclear ribosomal DNA is the most popular region for molecular phylogenetic studies for diverse plant groups including orchids, although it has some conspicuous drawbacks such as APS due to incomplete concerted evolution (NietoFeliner 2003). APS are observed when two nucleotides involved in a polymorphic site and those are very common when a hybridisation event on the background (Fuertes Aguilar \& Nieto-Feliner 2003). Concerted evolution concept described as a genetic process by which repetitive DNA sequences are homogenized among the genome of different species, and it is known that the ITS has concerted evolution characteristic (Liao 2008). APS are indicative of incomplete concerted evolution due to a hybridisation event has not been homogenized within the genome (Bailey 2003). Those polymorphic ITS copies have been reported by authors in the literature (Mayol \& Rosselló 2001, Won \& Renner 2005). Our sequencing results revealed that the ITS has APS on the sequence chromatogram data (Figure 2). This finding refers to a hybridisation event and incomplete concerted evolution on Neotinea spp. particularly distributed in Asia Minor. These circumstances had an impact on the resolution power and caused sample misplacements on the phylogenetic trees. Additionally, incomplete concerted evolution of ITS marker on Neotinea spp. is in contradiction with the DNA barcode concept, since double nucleotide peaks are common throughout the sequence.

Our two phylogenetic trees have provided contrasting results for closely related Neotinea spp. On the ITS tree, $N$. tridentata samples from Adana, Trabzon, Antalya (Turkey), Siklos (Hungary), Ucka (Croatia) and Pelion (Greece) were separated from other $N$. tridentata samples due to having APS which comes from different copies of the ITS sequence in the genome. On the phylogram (Figure 3) it is also seen that $N$. tridentata samples from Adana, Trabzon and Antalya separated from other samples collected from Turkey. The issue with ITS region was discussed extensively in the study of Nieto-Feliner \& Rosselló (2007). In the study, the authors listed the drawbacks of the ITS region and stressed its multi-copy nature which causes less confident results on phylogenetic studies. On the other study on which ITS was used, neither direct sequencing nor cloning efforts provided sufficient data for the phylogeny of Himantoglossum W.D.J. Koch s.l. (Orchidaceae) (Sramkó et al. 2011). In our study, in contrast to the study of (Pridgeon et al. 1997), the resolution power of the ITS region was insufficient to separate closely related $N$. tridentata and $N$. ustulata species that we sampled.

Our second molecular phylogenetic tool, accD-psaI region, performed better than ITS for the topology of the phylogenetic tree. On the tree, $N$. tridentata and $N$. ustulata species were separated except one $N$. ustulata sample from Varpalota (Hungary). When we compared the topologies of our two phylogenetic trees side-by-side, the incongruence is clear. While acc D-psaI separate $N$. tridentata and $N$. ustulata, ITS does not. The contrasting incongruences on the two differently inherited molecular markers, i.e. cpDNA and ITS, refer to a hybridisation (Rieseberg et al. 1996; Gulyás et al. 2005; Sramkó et al. 2008; Kim \& Donoghue 2008; Sramko et al. 2014). In our results, the clear incongruence refers to the complex history of Neotinea genus and possible hybridisation between $N$. tridentata and $N$. ustulata, also. ITS region failed at the genus Neotinea since incomplete concerted evolution and hybridization background causes double-peaks and additive polymorphic sites on the sequence.

According to the statistics, in the 66\% of papers published between 1998 and 2002, the ITS was used and 34\% of them used ITS as the only molecular marker (Álvarez \& Wendel 2003). This statistic shows the popularity of the ITS marker in the beginning and the improvement stage of the molecular phylogenetic studies. Later, after 2005 to date, the rate of ITS usage as the only molecular marker was decreased to $15.7 \%$, and other molecular markers, i.e. mitochondrial or chloroplast sequences, were included to support the data gathered from the ITS (Nieto-Feliner \& Rossello 2007) that indicated the doubts on the ITS and attempts to find new molecular markers. 

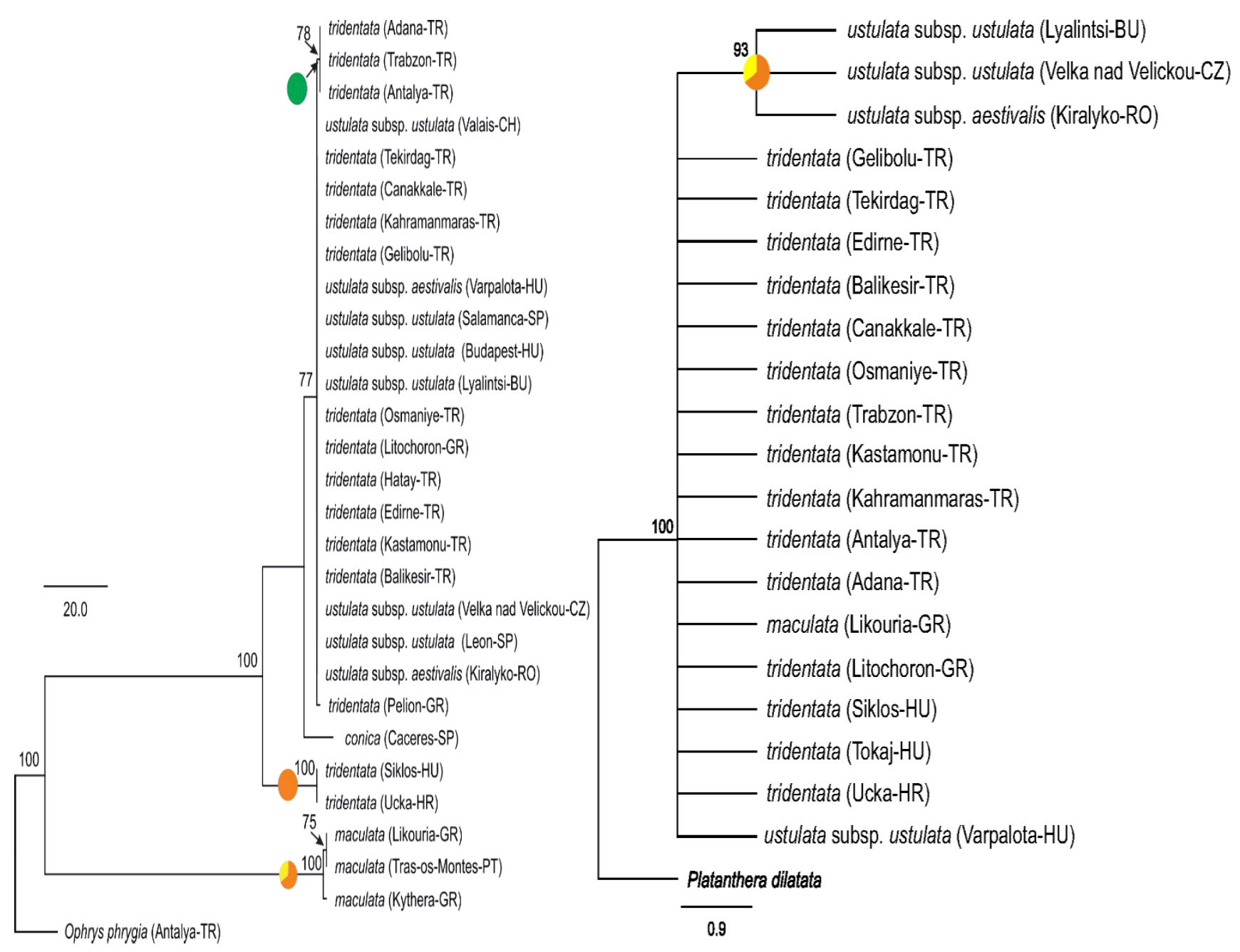

Figure 3- A: MP Phylogram of Neotinea spp. based on ITS sequences. The regions of origin are shown in parenthesis as country codes. $O$. phrygia is selected as the out-group. B: MP Cladogram of Neotinea spp. based on acc D-psaI sequence. The regions of origin are shown in parenthesis as country codes. Bootstrap-support values are shown on nods. $P$. dilatata is selected as the out-group. The pie chart represents the regions where differentiated samples collected from

\section{Conclusions}

On the history of molecular markers, the ITS region is still popular. It is not possible to abandon ITS as a molecular marker from the recent phylogenetic studies, particularly on orchids. However, researchers who study closely related species such as Neotinea spp., must consider the drawback of the marker. The strong conflicts between ITS and accD-psaI point out a possible hybridisation story. Fortunately, there are new technological ways of securing correct reconstruction of molecular phylogenetic trees and barcoding the closely related species, e.g. utilization of Next Generation Sequencing (NGS) techniques like RAD-seq.

\section{Acknowledgements}

We are grateful to Dr Gábor Sramkó for sharing his Neotinea spp. collection and his contributions improving the manuscript. We thank Cathy Seither for language proofing. This study was financially supported by Çanakkale Onsekiz Mart University, Scientific Research Coordination Unit; Project number: BAP FBA-2015-415. This study is based on the Doctoral Thesis titled "Studies on Phylogenetic Analysis of Neotinea ustulata and Neotinea tridentata (Orchidaceae)" written by Kaan Hürkan.

\section{Supplementary Table}

The whole list of the specimens sampled is available on Table S1 with the GenBank-accession numbers.

\section{References}

Álvarez I \& Wendel J F (2003). Ribosomal ITS sequences and plant phylogenetic inference. Molecular Phylogenetics and Evolution 29(3): 417-434 doi: 10.1016/S1055-7903(03)00208-2 
Bailey C (2003). Characterization of angiosperm nrDNA polymorphism, paralogy, and pseudogenes. Molecular Phylogenetics and Evolution 29(3): 435-455 doi: 10.1016/j.ympev.2003.08.021

Baldwin B G, Sanderson M J, Porter J M, Wojciechowski M F, Campbell C S \& Donoghue M J (1995). The its Region of Nuclear Ribosomal DNA: A Valuable Source of Evidence on Angiosperm Phylogeny. Annals of the Missouri Botanical Garden 82(2): 247-277

Bateman R M, Hollingsworth P M, Preston J, YI-BO L, Pridgeon A M \& Chase M W (2003). Molecular phylogenetics and evolution of Orchidinae and selected Habenariinae (Orchidaceae). Botanical Journal of the Linnean Society 142(1): 1-40 doi: 10.1046/j.10958339.2003.00157.x

Chase M W, Fay M F \& Savolainen V (2000). Higher-level classification in the angiosperms: new insights from the perspective of DNA sequence data. Taxon 49: 685-704

Doyle J J \& Doyle J L (1990). Isolation of plant DNA from fresh tissue. Focus (San Francisco, California), 12: 13-15

Fuertes Aguilar J \& Nieto-Feliner G (2003). Additive polymorphisms and reticulation in an ITS phylogeny of thrifts (Armeria, Plumbaginaceae). Molecular Phylogenetics and Evolution 28(3): 430-447 doi: 10.1016/S1055-7903(02)00301-9

Gulyás G, Sramkó G, Molnár V A, Rudnóy S, Illyés Z, Balázs T \& Bratek Z (2005). Nuclear ribosomal DNA ITS paralogs as evidence of recent interspecific hybridization in the genus Ophrys (Orchidaceae). Acta Biologica Cracoviensia Series Botanica 47(2): 61-67

Hollingsworth P M (2008). DNA barcoding plants in biodiversity hot spots: progress and outstanding questions. Heredity (Edinb) 101(1): 1-2 doi: $10.1038 /$ hdy.2008.16

Kearse M, Moir R, Wilson A, Stones-Havas S, Cheung M, Sturrock S \& Drummond A (2012). Geneious Basic: An integrated and extendable desktop software platform for the organization and analysis of sequence data. Bioinformatics 28(12): 1647-1649 doi: 10.1093/bioinformatics/bts199

Kim S T \& Donoghue M J (2008). Incongruence between cpDNA and nrITS trees indicates extensive hybridization within Eupersicaria (Polygonaceae). American Journal of Botany 95(9): 1122-1135 doi: 10.3732/ajb.0700008

Larkin M A, Blackshields G, Brown N P \& et al. (2007). Clustal W and Clustal X version 2.0. Bioinformatics 23(21): 2947-2948 doi: 10.1093/bioinformatics/btm404

Li X, Yang Y, Henry R J, Rossetto M, Wang Y \& Chen S (2015). Plant DNA barcoding: from gene to genome. Biological Reviews 90(1): 157166 doi: $10.1111 /$ brv. 12104

Liao D (2008). Concerted Evolution. In: John Wiley \& Sons Ltd. Encyclopedia of Life Sciences. Chichester, UK, pp. 1-5 doi: 10.1002/9780470015902.a0005132.pub2

Mayol M \& Rosselló J A (2001). Why Nuclear Ribosomal DNA Spacers (ITS) Tell Different Stories in Quercus. Molecular Phylogenetics and Evolution 19(2): 167-176 doi: 10.1006/mpev.2001.0934

Nieto-Feliner G N \& Rosselló J A (2007). Better the devil you know? Guidelines for insightful utilization of nrDNA ITS in species-level evolutionary studies in plants. Molecular Phylogenetics and Evolution 44(2): 911-919 doi: 10.1016/j.ympev.2007.01.013

Pillon Y, Fay M F, Hedrén M, Bateman R M, Devey D S, Shipunov A B, van der Bank M, Chase M W \& Hedren M (2007). Evolution and temporal diversification of western European polyploid species complexes in Dactylorhiza (Orchidaceae). Taxon 56(4): 1185-1208 doi: $10.2307 / 25065911$

Pridgeon A M, Bateman R M, Cox A V, Hapeman J R \& Chase M W (1997). Phylogenetics of subtribe Orchidinae (Orchidoideae, Orchidaceae) based on nuclear ITS sequences. 1. Intergeneric relationships and polyphyly of Orchis sensu lato. Lindleyana 12(3): 89-109

Rieseberg L H (1997). Hybrid origins of plant species. Annual Review of Ecology, Evolution, and Systematics 28(1): 359-389 doi: 10.1146/annurev.ecolsys.28.1.359

Rieseberg L H, Whitton J \& Linder C R (1996). Molecular marker incongruence in plant hybrid zones and phylogenetic trees. Acta Botanica Neerlandica 45(3): 243-262

Shipunov A B, Fay M F, Pillon Y, Bateman R M \& Chase M W (2004). Dactylorhiza (Orchidaceae) in European Russia: Combined molecular and morphological analysis. American Journal of Botany 91(9): 1419-1426 doi: 10.3732/ajb.91.9.1419

Small R L, Ryburn J A, Cronn R C, Seelanan T \& Wendel J F (1998). The tortoise and the hare: Choosing between noncoding plastome and nuclear ADH sequences for phylogeny reconstruction in a recently diverged plant group. American Journal of Botany 85(9): 1301-1315 doi: $10.2307 / 2446640$

Sramko G, Attila M V, Hawkins J A \& Bateman R M (2014). Molecular phylogeny and evolutionary history of the Eurasiatic orchid genus Himantoglossum s.l. (Orchidaceae). Annals of Botany 114(8): 1609-1626 doi: 10.1093/aob/mcu179

Sramkó G, Gulyás G, Matus G, Rudnóy S, Illyés Z, Bratek Z \& Molnár A (2008). Leaf width, nrDNA and cpDNA its sequence variation within central European Bulbocodium vernum and B. versicolor (Colchicaceae) populations: Are there really two taxa? Acta Biologica Academiae Scientiarum Hungaricae 59: 103-114

Sramkó G, Molnár V A, Hawkins J A \& Bateman R M (2011). Evolution of the Eurasiatic genus Himantoglossum(Orchideae, Orchidoideae): An integrativephylogenetic approach. XVIII International Botanical Congress. Melbourne, pp. 286-287

Swofford D L (2003). PAUP*. Phylogenetic Analysis Using Parsimony (*and Other Methods). Version 4. Sinauer Associates, Sunderland, Massachusetts

The Plant List (2013). Retrieved in May, 24, 2018 from http://www.theplantlist.org

White T J, Bruns T D, Lee S \& Taylor J W (1990). Amplification and direct sequencing of fungal ribosomal RNA genes for phylogenetics. In: Innis, M.A., Gelfand, D.H., Sninsky, J.J. \& White, T.J. (Eds.) PCR protocols: A guide to methods and applications. Academic Press, SanDiego, pp. 315-322

Won H \& Renner S S (2005). The internal transcribed spacer of nuclear ribosomal DNA in the gymnosperm Gnetum. Molecular Phylogenetics and Evolution 36(3): 581-597 doi: 10.1016/j.ympev.2005.03.011

Zimmer E A \& Wen J (2012). Using nuclear gene data for plant phylogenetics: Progress and prospects. Molecular Phylogenetics and Evolution 65(2): 774-785 doi: 10.1016/j.ympev.2012.07.015 
Supplementary Table S1. Table of Sampling and GenBank accession numbers*

\begin{tabular}{|c|c|c|c|}
\hline \multirow[t]{2}{*}{ Sample } & \multicolumn{2}{|c|}{$\begin{array}{c}\text { GenBank Accession } \\
\text { Number }\end{array}$} & \multirow[t]{2}{*}{ Collecting site } \\
\hline & nrITS & accD-psaI & \\
\hline N. conica & AY364880 & - & Caceres-Spain \\
\hline N. maculata & AM711744 & - & Kythera-Greece \\
\hline N. maculata & MH050840 & MH400962 & Likouria-Greece \\
\hline N. maculata & AY364873 & - & Tras os Montes-Portugal \\
\hline N. tridentata & MH050841 & MH400963 & Adana-Turkey \\
\hline N. tridentata & MH050842 & MH400964 & Antalya-Turkey \\
\hline N. tridentata & MH050843 & MH400965 & Balıkesir-Turkey \\
\hline N. tridentata & MH050844 & MH400966 & Çanakkale-Turkey \\
\hline N. tridentata & MH050845 & MH400967 & Edirne-Turkey \\
\hline$N$. tridentata & MH050846 & MH400968 & Gelibolu-Turkey \\
\hline N. tridentata & MH050847 & - & Hatay-Turkey \\
\hline N. tridentata & MH050848 & MH400969 & Kahramanmaraş-Turkey \\
\hline N. tridentata & MH050849 & MH400970 & Kastamonu-Turkey \\
\hline N. tridentata & MH050850 & MH400971 & Litochoron-Greece \\
\hline N. ustulata subsp. ustulata & MH050858 & MH400980 & Lyalintsi-Bulgaria \\
\hline N. tridentata & MH050851 & MH400972 & Osmaniye-Turkey \\
\hline N. tridentata & KF499509 & & Pelion-Greece \\
\hline N. tridentata & MH050852 & MH400973 & Siklos-Hungary \\
\hline N. tridentata & MH050853 & MH400974 & Tekirdağ-Turkey \\
\hline N. tridentata & MH050854 & MH400976 & Trabzon-Turkey \\
\hline N. tridentata & - & MH400975 & Tokaj-Hungary \\
\hline N. tridentata & MH050855 & MH400977 & Uçka-Croatia \\
\hline N. ustulata subsp. ustulata & FR750397 & - & Budapest-Hungary \\
\hline N. ustulata subsp. ustulata & AY364883 & - & Leon-Spain \\
\hline N. ustulata subsp. ustulata & AY364883 & - & Salamaca-Spain \\
\hline N. ustulata subsp. ustulata & AY014549 & - & Valais-Switzerland \\
\hline N. ustulata subsp. aestivalis & MH050857 & MH400979 & Varpalota-Hungary \\
\hline N. ustulata subsp. ustulata & MH053407 & MH400981 & $\begin{array}{c}\text { Velka nad Velickou- } \\
\text { Czechia }\end{array}$ \\
\hline N. ustulata subsp. aestivalis & MH050856 & MH400978 & Kiralyko-Romania \\
\hline Ophrys phrygia & MH050859 & - & Antalya-Turkey \\
\hline Platanthera dilatata & - & JX484921 & - \\
\hline Neotinea tridentata & - & - & Toskana-Italy \\
\hline Neotinea tridentata & - & - & Monte Gargano-Italy \\
\hline
\end{tabular}

*The dashes represents no reliable sequencing quality or data not available on GenBank. 